\title{
The tapestry of Dolakha Newar: Chaining, embedding, and the complexity of sentences
}

\author{
CAROL GENETTI
}

\begin{abstract}
In Dolakha Newar the boundaries of syntactic sentences are clearly demarcated. However, each tightly-bounded sentence has the potential for infinite expansion and structural complexity. This results from the recursive interaction of two basic combinatorial structures: chaining and embedding. While these structures are basic to many of the world's languages, in Dolakha Newar speakers combine them freely and frequently to spontaneously create sentences of remarkable intricacy. Additional structural nuance is provided by the chaining of constituents at levels below the clause and the sharing of core arguments. The result is a syntactic fabric of depth and complexity.

Keywords: clause chaining, clause combining, converb, discourse structure, Newar, recursion, speech reporting, syntactic complexity, syntax, Tibeto-Burman
\end{abstract}

\section{Introduction}

Many languages well known in linguistic typology possess a feature, or a set of features, which is remarkable in systematic efficiency and central to its design, an axis around which other grammatical subsystems revolve. Some examples of this, in my view, include Yup'ik polysynthesis, Philippine voice systems, Lahu verb concatenation, Nez Perce transitivity markers, and Latin case. ${ }^{1}$ Each of these systems constitutes a structural core of the language around which the grammar is organized.

1. Yup'ik polysynthesis, Latin case, and Philippine voice systems are well known. For Lahu verb concatenation, see Matisoff 1969, 1973: 199-265. For Nez Perce transitivity markers, see Rude 1985, 1986. 
In Dolakha Newar, a Tibeto-Burman language spoken in Nepal, an essential structural core is found in the combination of clauses, which produces sentences with remarkable levels of syntactic complexity. This complexity, however, results from the interaction of quite simple principles of design: chaining and embedding. These principles are hardly unique to Dolakha Newar - indeed the structures are quite ordinary from a typological perspective - but their particular instantiation in this language allows speakers to produce tightlybounded sentences of remarkable structural variation and complexity. They do this freely and frequently in the production of connected discourse, which is characterized by an intricate interweaving of structures, creating a syntactic fabric of depth, subtlety, and complexity.

\section{Background information}

\subsection{Broader context}

The term "Newar" refers to a politically significant ethnic group of TibetoBurman origin who for many centuries were the rulers of the Kathmandu Valley and outlying areas in Nepal. The Newar people are known for their rich intellectual and material culture. They experienced a remarkable period of renaissance between the twelfth and seventeenth centuries, when they made significant developments in music, dance, art, architecture, craftsmanship, drama, literature, poetry, and religious philosophy. Manuscripts written in Classical Newar date back to the twelfth century.

There are many Newar language varieties, and some of these, such as Dolakha Newar, are mutually unintelligible with the varieties spoken in the Kathmandu Valley. Therefore, in purely linguistic terms, "Newar" should be thought of as a small family of languages, as opposed to a single language with many dialects. In the linguistic literature, however, the terms "Newar" and "Newari", when used without modification, typically refer to the variety of Newar which is spoken in Kathmandu, the politically dominant center of the Newar ethnic group and the country of Nepal.

The size and shape of the Newar family have yet to be determined, as there are only a few studies of the Newar varieties spoken outside of the Kathmandu Valley. It is clear, however, that there are at least three branches of the family: Eastern, Central, and Western. Dolakha Newar is a member of the Eastern branch, together with the Tauthali variety and those of other local municipalities.

Moving up in the stammbaum, we know that Newar is a member of the Bodic branch of the Tibeto-Burman language family. There have been a number of suggestions as to the sub-grouping of Newar within Bodic. These include the following: with Chepang in West Central Himalayish (Glover 1970); with Chepang, Magar, and Kham in Central Himalayish (Bradley 1997); with 
Tamang, Gurung, Thakali, and Manange in Tamangic (Kansakar 1999); with Gyarong and Mishmi (Voegelin \& Voegelin 1977); with the Kiranti languages (Benedict 1972, Genetti 1994, van Driem 2001); or outside the Kiranti nucleus but, with Thangmi and Baram, forming a close sister in a sub-branch called "Para-Kiranti" (van Driem 2004). Before any of these hypotheses can be definitively tested, further descriptive work on Newar varieties and internal reconstruction within Newar is needed.

Geographically, Dolakha Newar is spoken approximately 145 kilometers to the east of Kathmandu, in the Dolakha district of the Janakpur zone. The elevation varies between 1,700 and 1,830 meters, about 5,500 to 6,000 feet. The municipality of Dolakha has a long history; it dates back at least as far as the thirteenth century, and was possibly established much earlier. Thus the split of the Dolakha and Kathmandu Valley varieties of Newar occurred at least 700 years ago.

In the current day, only a minority of the Dolakha Newar community remains in Dolakha proper. Most young people leave Dolakha for Kathmandu or other urban areas to pursue educational and employment opportunities. Even in the "Dolakha diaspora", however, people maintain strong social and family bonds and there are a number of active civic organizations dedicated to the improvement of Dolakha and its people.

It is difficult to know the number of speakers of the language. Members of the community have provided an estimate of 5,000. It is clear, however, that there is a strong trend toward marriage with Newars from outside the Dolakha community. Often in these households Nepali is the primary language and the children are rarely exposed to Dolakha Newar. Thus the rate of language transmission to the younger generations (i.e., those below the age of twenty-five) is low. According to Fishman's stages for reversing language shift, Dolakha is at about Stage 7, where "cultural interaction in Xish [the endangered language - CG] primarily involves the community-based older generation" (Fishman 2001: 465-469).

\subsection{Basic clause-level morphology and syntax}

Dolakha Newar is a verb-final language. The unmarked ordering of the primary constituents of the clause is SV for intransitive clauses, AOV for transitive clauses, and AORV, with R indicating the second object denoting a recipient, for ditransitive clauses (Genetti 2007: 320-329).

Transitivity is a significant morphosyntactic dimension in this language, as intransitive and transitive verbs are distinguished morphologically (Genetti 2007: 154). Ditransitive verbs are morphologically classed with transitive verbs, but take a second object that indicates the recipient argument.

Ergative case-markers are consistently found on the A arguments of transi- 
tive and ditransitive verbs, whereas $\mathrm{S}$ arguments and non-human $\mathrm{O}$ arguments are unmarked. There is no indication of any sort of a split in the ergative patterning; if the verb is morphologically transitive, the A argument will take the ergative case-marker (Genetti 2007: 106-110).

There is clear evidence of grammatical subjects and objects in this language. A full discussion is beyond the scope of this article; for further information, see Genetti (2007: 307-317). Here I will note only that verbs are marked for the person, number and honorific status of the $\mathrm{S}$ argument of intransitive clauses and the A argument of transitive and ditransitive clauses, so verb agreement alone clearly identifies a grammatical subject.

All transitive clauses may take a grammatical object. Ditransitive clauses may take two grammatical objects, one representing the patient and one the recipient. There is no evidence that these two types of object are grammatically distinct from each other (Genetti 1997, 2007: 113-115). Objects are marked with the dative case-marker if they are human and given. Note that it is possible for both objects in a ditransitive clause to be case-marked, as in (1): ${ }^{2}$

$$
\begin{aligned}
& \text { āle }[\bar{a} m t a]_{O} \quad[\text { bhänche=ta }]_{R E C} \text { bir-ju } \\
& \text { then 3sG.DAT cook=DAT } \\
& \text { 'Then he gave her (in marriage) to the cook.PST }
\end{aligned}
$$

The basic case-marking patterns of the language are:

(i) subjects of intransitive verbs are not case-marked,

(ii) subjects of transitive verbs take the ergative case-marker, and

(iii) objects take the dative case-marker if they are human and given.

\section{Syntactic sentences: The architecture of embedding and chaining}

\subsection{Sentences and their sequencing}

Dolakha Newar narrative, the discourse genre on which this study is primarily based, consists of a series of syntactic sentences in linear order, each with a strongly marked right boundary, resulting from the production of a nonembedded finite verb. ${ }^{3}$ This may be followed by one of a small set of particles or - only occasionally in narrative discourse - right-dislocated arguments, postpositional phrases, or other adjuncts. Typically, sentence beginnings in narratives are marked by one or more clauses which recapitulate the events denoted at the end of the previous sentence (Genetti 2007: 438-439). This discourse pattern is referred to as "tail-head linkage" (Longacre 1968: 8-9, 1985; Thompson \& Longacre 1985: 209-210; de Vries 2005) or as a "bridging device" (Dixon 2009: 8).

\footnotetext{
2. All examples in this article are taken from continuous narrative discourse.
}

3 . The exception to this occurs when copulas are elided. 
Example (2) illustrates a typical transition from one sentence to the next. The first line represents the final clause of a multi-clause sentence. It ends in a nonembedded finite verb, here inflected with the 3rd person singular past suffix. The next sentence then starts with a clause which recapitulates the final event of the preceding sentence, repeating the object noun phrase and the verb hār'bring'. In this clause, the verb is in participial form, instantiating a chaining structure:

$$
\begin{aligned}
& \text { āmun jāki hār-ju. } \\
& \text { 3sG.ERG uncooked.rice bring-3sG.PST } \\
& \text { '... he brought (home) rice. } \\
& \text { jāki hā-ene māuri=ta hat-cu. } \\
& \text { uncooked.rice bring-PART mother=DAT say-3sG.PST } \\
& \text { Bringing the rice, he spoke to his mother.' }
\end{aligned}
$$

\subsection{Basic architectural principles: Embedding and chaining}

There are two primary architectural principles which underlie the construction of the Dolakha Newar complex sentence: embedding and chaining. Each of these principles may be realized by multiple syntactic constructions. Embedding can occur within the noun phrase through relative clause and nominal complement constructions, both of which involve the nominalization of the embedded verb (Genetti 2007: 388-394). Embedding also occurs via complementation, when entire clauses are embedded as full noun phrases (Genetti 2007: 408-424). This includes the embedding of direct speech as syntactic objects of cognition or utterance verbs.

The primary chaining constructions include adverbial clauses and what I call the "participial construction" (Genetti 2007: 460-484); these two may be subsumed under the broader category of "converbal construction", although they are, in fact, quite distinct. Chaining can also include the sequencing of multiple distinct sentences within an embedded structure.

3.2.1. Embedding Embedding entails the inclusion of a clause within or as a syntactic argument of a superordinate clause. We can see this, with a relative clause, in (3):

(3) $\left[[\varnothing \text { ām pipāna ye-u }]_{\mathrm{REL}} m i=p e n\right]_{\mathrm{NP}-\mathrm{S}}$ gun? that verandah come-NR1 person=PL who

'Who are the people who came to the verandah?'

In complementation structures, the elaborating clause comprises the noun phrase as a whole. This can be seen in (4), where the complement clause is the entire syntactic object of the complement-taking predicate: 


\section{(4) dokhsenuy $[\text { kharāyo lipul-e }]_{\mathrm{NP}-\mathrm{O}}$ khoy-an}

all.ERG rabbit return-NR2 see-PART

'All of them seeing the rabbit return ...'

There is one type of complement in Dolakha Newar, however, which may be typologically unusual (Dixon 2006: 10,28). This is the embedding of direct quotes as object complements of cognition or utterance verbs, as in (5):

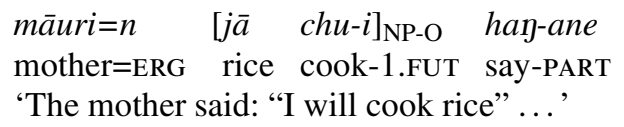

In this example, $j \bar{a}$ chu- $i$ forms a complete syntactic sentence as it ends in a finite verb; there is no structural difference between this unit embedded into a quotative frame and the identical sentence uttered in a free-standing context. Here, however, the quoted material is the grammatical object of the verb hat'say'.

Evidence that embedded direct quotes constitute grammatical objects of cognition or utterance verbs is found in the highly integrated nature of quotative sentences. Cognition and utterance verbs are syntactically transitive or ditransitive, with ergative-marked subjects and transitive suffixal morphology. Quotative complements exhibit the same patterns of positioning as simple nominal objects, generally coming between the ergative subject and the verb, creating an integrated AOV structure. This structure is not rigid; again like nominal objects, quotative complements can precede the A argument under defined discourse conditions. Finally, syntactically analyzing direct quotations as anything other than object complements turns out to be highly problematic; see Genetti \& Slater 2004 for discussion.

Embedding architecture places a clause entirely within another element, either a noun phrase or another clause. We can represent this schematically as in Figure 1.

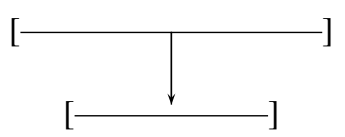

Figure 1. Basic embedding architecture

Embedding is denoted by a change in the vertical dimension, following the tradition of syntactic trees. Figure 1 does not represent any particular example, so does not include labels for constituents. With embedding it is useful to roughly note the position of the noun phrase where the embedding occurs, so for this type of architecture, simple labels for NPs and Vs will be included in 
the structural representations of particular examples. Thus, example (5) can be represented as in Figure 2. To simplify the diagrams and focus on the structural complexity of the examples, the transcription and glosses will generally not be included in the figures.

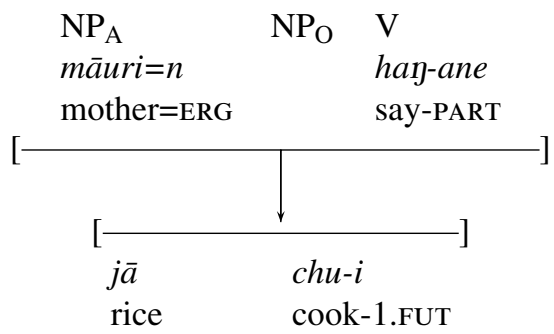

Figure 2. Example (5): An embedded object complement clause

So far I have presented examples of embedded structures that are syntactically simple. Such examples are actually quite rare in narrative discourse. This is because embedded elements of any type can be expanded into chains.

3.2.2. Chaining Chaining architecture creates sequential strings of clauses which occupy the same level of syntactic structure. While embedding can be conceptualized as reflecting a vertical relationship between the elements, chained structures can be conceptualized horizontally, reflecting their syntagmatic character.

As mentioned above, I differentiate two types of chaining structures, adverbial and participial clauses. ${ }^{4}$ These two types have similar syntactic properties and can be subsumed under the general label of (Asian) converb, ${ }^{5}$ with the participial clauses being the "general" or "contextual" converb and adverbial clauses being "specific" converbs (König 1995: 58). The difference between these is that adverbial clauses are marked by a suffix which specifically denotes the interpropositional relationship between the adverbial clause and the following clause. Participial suffixes are not semantically specific, leaving the interpropositional relationship to be inferred contextually.

Syntactically, the two structures share many of the same properties. Critically, both types of clauses are dependent (both morphologically and distributionally) but not subordinate (Genetti 2005, 2007: 452-455, 477-482).

4. The term "participial" is the traditional term used in Newar linguistics; it represents a shortening of "conjunctive participle", a term commonly used in South Asian linguistics (see, e.g., Masica 1991: 399-401).

5. For discussion of the term "Asian converb", see Bickel 1998 and Genetti 2005. 
There are important differences between adverbial and participial clauses. The asyndetic nature of the participial suffix allows for the wide functional range and frequency of the construction, including its use in creating chains of multiple linked clauses, which can have a variety of interpropositional relationships. It also sets the stage for grammaticalization to occur, so that participial clauses co-occur with auxiliary verbs, other grammaticalized constructions, and in collocations. By contrast, adverbial clauses, with their specific semantic content, are functionally limited. They typically do not form chains and they tend to be sentence-initial, conveying background information with respect to the following clauses. This comparatively restricted distribution also means that they rarely occur with sufficient frequency or in a broad enough context to allow the formation of collocations or grammaticalized constructions. Thus adverbial clauses and participial clauses, while having similar behavior with regards to specific morphological and syntactic properties, are quite distinct in terms of usage.

Examples $(6 a-c)$ illustrate temporal, conditional, and causal adverbial clauses respectively. These are typical examples, but chosen for their simplicity. 6
a. janchi phen-yasin ām swālhār-a sash untie-when that fall-3sG.PST 'When he untied his sash, that fell.'

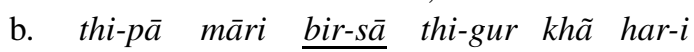 one-CL bread give-if one-CL talk say-1.FuT 'If you give me one (piece of) bread, I will tell you one thing.'
c. āme hatār ju-e-lägin bimesor thākur=ta 3sG.GEN haste be-NR2-because Bimsen lord=DAT catan=na pwāl-ju spoon=INST strike-3sG.PST 'Because of his haste, he struck Lord Bimsen with a spoon.'

Examples $(7 a-c)$ show typical uses of the participial construction. In (7a) the two linked clauses share a single subject, whereas in (7b) the subjects are distinct. Example (7c) shows a fairly typical sequence of chained clauses, which is only unusual in the reiteration of the subject argument in the final clause.
(7) a. àmun jā na-en $\quad$ ye-eu $k a$
3SG.ERG rice eat-PART come-3.FUT ASS
'He will eat his meal and come back.'

6. To help clarify the structure of the examples, chained verbs will be underlined. Embedded clauses will be put into labeled brackets. 


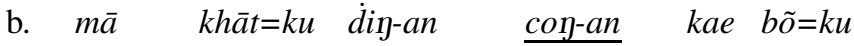
mother bed=LOC sleep-PART stay-PART son floor=LOC con- $a$ stay-3sG.PST

'The mother was sleeping on the bed; the son sat on the floor.'

c. ām kehẽ=uri sut-pānt phi-ene tap phi-en

that younger.sister=IND suit-pant wear-PART hat wear-PART

sara ga-en àm kehe tuj on-a

horse climb-PART that younger.sister FOC go-3sG.PST

'That younger sister put on a pants suit, put on a hat, climbed on a horse, and that younger sister went.'

Although the final clause in the chain carries the finite morphology, there is no other way that it is syntactically or rhetorically privileged. Referring it to as "main", "matrix", or "superordinate" suggests an asymmetric structure which is unwarranted for this construction (for further discussion on this point, see Genetti 2005: 75-81). The final clause carries the finite morphology because the speaker chose to end the sentence at that point. This may well be at the end of an episode, but the final clause is not necessarily the most important of the sentence in rhetorical terms. An example of this is given in (8), which is taken from a story illustrating the cleverness of a man who outsmarted some parrots that had been eating the rice from his fields. It is the taking of the money which indicates his triumph, not his leaving:

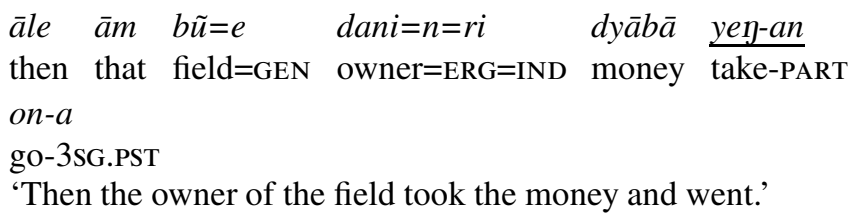

The rhetorical relationships between the clauses are contextually, not syntactically, determined.

Chaining structures will thus be represented by a non-hierarchical horizontal architecture, as shown in Figure 3. Applied to (6a), this diagramming technique produces the simple structure exemplified in Figure 4.

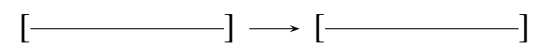

Figure 3. Basic chaining architecture 


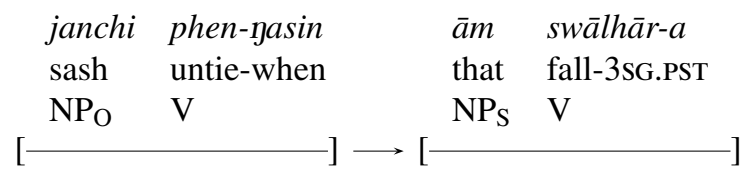

Figure 4. Example (6a): A simple chain of two clauses

\section{Creating complexity: Chains within embeddings, embeddings within chains}

In Dolakha Newar narrative discourse, chaining and embedding architectures are combined freely in unplanned connected discourse. Any embedded structure can contain chains within it, and any clause or noun phrase can contain an embedding. Recursion is robust and seemingly applied with abandon, creating syntactic edifices of remarkable complexity.

We will begin with a relatively simple example, the use of a chain within an embedded relative clause:

$$
\begin{aligned}
& \text { [[ämun hā-en ta-e } \left.]_{R E L} \text { ni-sar dyābā }\right]_{\mathrm{NP}-\mathrm{O}} \quad \bar{a} m u \\
& \text { 3SG.ERG bring-PART keep-NR2 two-hundred money that } \\
& \text { che dani=n kār-ai } \\
& \text { house owner=ERG take-3sG.PR } \\
& \text { 'The householder took the two-hundred rupees that he had brought and }
\end{aligned}
$$

Here we have a simple OAV clause, but the $\mathrm{O}$ is complex, containing within it the relative structure "that he had brought and kept with him". The structure of this example is represented in Figure 5.

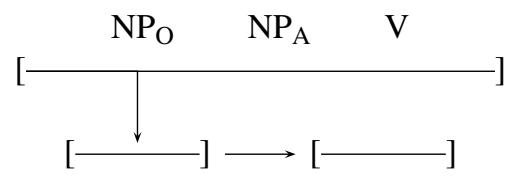

Figure 5. Example (9): Two chained clauses embedded as a relative within an object $N P$

Example (10) is taken from the same narrative. The relative clause has the same structure as in (9), but in this example, the noun phrase that contains the relative clause functions as the object of an infinitive clause which is the syntactic complement of the verb mal-a 'must': 


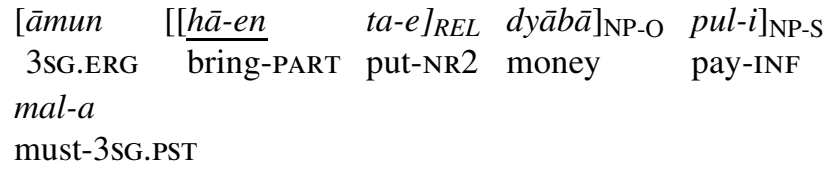

'(He) must pay the money he has brought and has with him.' ${ }^{7}$

Thus we have a chain embedded as a relative within an object noun phrase, which is itself within a clause embedded as a complement. This structure is represented in Figure 6.

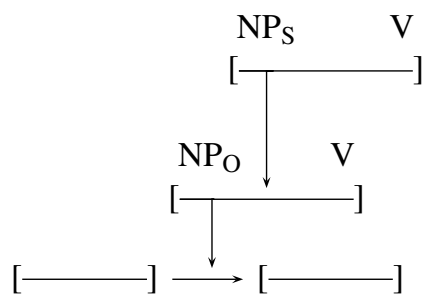

Figure 6. Example (10): Two chained clauses embedded within a relative in an object $N P$, which in turn is in a clause embedded as a subject complement

Increasing complexity is found in example (11). The top-level structure is a chain of three clauses, with the verbs sukā-en 'pretend', hä-en 'bring', and $b i-u$ 'give', respectively. The verb of the first clause, suk $\bar{a}-e n$ 'pretend', is a complement-taking predicate, so has an object complement with the predicate sumake na-e 'silently eating'. The object of the verb na-e 'eat' is in turn complex. It has a head noun cijbij 'things', modified by a repeated adjective $m \bar{a} s \bar{a} k u$ 'tasty', as well as by an embedded relative clause $c h \tilde{e}=k u=r i=n a$ chanta bi-e 'that they gave you from the house':

$$
\begin{aligned}
& {\left[\left[[c h \tilde{e}=k u=r i=n a \quad \text { chanta bi-e }]_{\mathrm{REL}} m \bar{a} s \bar{a} k u\right.\right. \text { māsāku }} \\
& \text { house }=\mathrm{LOC}=\mathrm{IND}=\mathrm{ABL} 2 \mathrm{SG} \text {.DAT give-NR2 untasty untasty } \\
& \text { cijbij] } \left.]_{\mathrm{NP}-\mathrm{O}} \text { sumake na-e }\right]_{\mathrm{NP}-\mathrm{O}} \text { sukā-en janta } \\
& \text { things silently eat-NR2 pretend-PART 1sG.DAT } \\
& h \bar{a}-e n \quad b i-u \\
& \text { bring-PART give-IMP } \\
& \text { 'Silently pretend to eat the not-tasty not-tasty food that they give you }
\end{aligned}
$$

7. The verb mal- 'must, be necessary' takes a subject complement. One cannot translate this literally into a grammatical English sentence. The translation 'His paying the money ... is necessary' is a bit closer to the Dolakha Newar original. 
Thus this example has a relative clause embedded within a noun phrase that is in a complement clause. The complement clause, in turn, is the syntactic object of a verb in a participial clause, which is chained with two other clauses. This structure is represented in Figure 7.

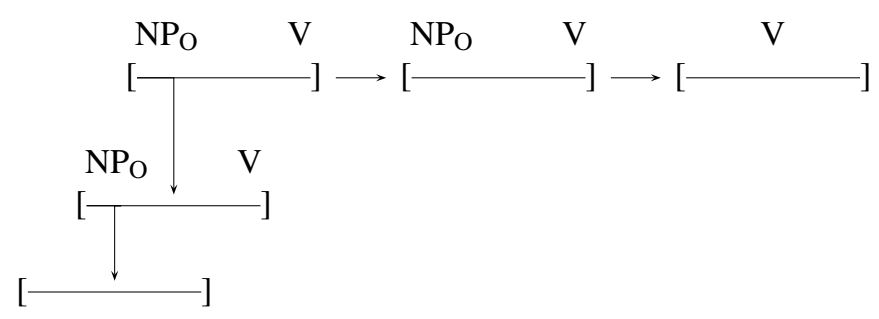

Figure 7. Example (11): A relative clause embedded into an object NP, which is within an embedded object complement, which is within the first clause of a participial chain

The chaining and embedding interactions become even more complicated when we consider the ubiquitous embedding of quoted speech. Quoted speech can contain not only sentences of any level of syntactic complexity; it can also contain multiple sentences. A simple example is given in (12):

$$
\begin{aligned}
& \text { āle pharsi=n [janta bu-en simā thābi ta-en } \\
& \text { then pumpkin=ERG 1sG.DAT carry-PART tree top put-PART } \\
& \text { bi-u jin sona kha-i }]_{\mathrm{NP}-\mathrm{O}} \text { hat-cu } \\
& \text { give-IMP 1sG.ERG flower pick-1.FUT say-3sg.PST } \\
& \text { 'Then the pumpkin said: "Carry me and put me on the top of the tree. } \\
& \text { I will pick the flower".' }
\end{aligned}
$$

Here we can see the basic AOV structure of the quotative sentence. However the embedded object complement is complex, consisting of two complete sentences. The first sentence contains a chain of three clauses (with the verbs bu-en 'carry', ta-en 'put', and bi-u 'give'). The second is the single clause jin sona $k h a-i$ 'I will pick the flower'. I view such linear ordering of sentences within embedded quotations as being another instantiation of chaining architecture. Thus the structure of this sentence can be represented as in Figure 8. Larger brackets are used to indicate full sentence boundaries. 


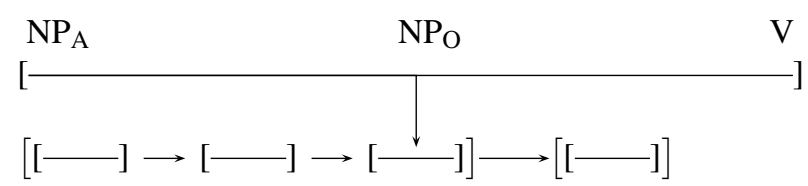

Figure 8. Example (12): A chain of two complete sentences, the first of which contains a chain, embedded as the object complement of a quotative verb.

As a final example, consider the sentence in (13), a single syntactic sentence of remarkable recursive depth:

a. Recapitulation

$\bar{a} m$ situgã $\tilde{a}$ tās yeng-an ta-ene

that grass stick do-PART put-PART

'Having put that grass by sticking,

b. Embedded quotation; syntactically the $\mathrm{O}$ of the quotative verb

$\mathrm{b}^{\prime} . \quad u \quad$ situg $\tilde{a} s \quad$ sir-sa

this grass die-COND

"If this grass dies,

$\mathrm{b}^{\prime \prime} . \quad[j i \quad$ dida sit- $a]$ hangan si- $u$

1SG elder.brother die-3SG.PST COMP know-IMP

know that I, your elder brother, died.

$\mathrm{b}^{\prime \prime \prime} . \quad u \quad$ situgã $\tilde{s}$ hāting ma-jur-sa,

this grass nothing NEG-happen-COND

If nothing happens to this grass,

$\mathrm{b}^{\prime \prime \prime \prime} . \quad[j i \quad m w \bar{a} t-a]$ hangan si-u.

1SG survive-3sG.PST COMP know-IMP

know that I survived."

c. Quotative verb

hang-an

say-PART

'so saying,

d. Final clause

jeth $\bar{a}=$ uri didā on- $a$.

elder=IND elder.brother go-3sG.PST

the older elder brother went.'

'Having stuck the grass (on the door), the elder brother said: "If this grass dies, know that I, your elder brother died. If nothing happens to this grass, know that I survived". So saying, the older elder brother left.' 
Putting aside the embedded quotation for the moment, we can see that the superordinate structure comprises four chained elements. Line (13a) has two chained verbs that share an object (see below). This structure is then chained with respect to lines (13c), the quotative verb in participial form, and (13d), the final line of the sentence, which contains the sentence-final non-embedded finite verb. Hence the superordinate structure can be represented as in Figure 9.

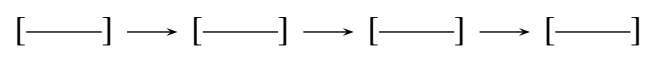

Figure 9. Superordinate structure of example (13): A chain of four clauses

The syntactic complication in this example comes from the embedded object complement of the third verb. This embedded material consists of two complete sentences of parallel structure. Each contains as its superordinate structure two chained clauses, the first in each case being conditional (lines $13 \mathrm{~b}^{\prime}$ and $13 \mathrm{~b}^{\prime \prime \prime}$ ) and the second being finite (lines $13 \mathrm{~b}^{\prime \prime}$ and $\left.13 \mathrm{~b}^{\prime \prime \prime \prime}\right)$. But the finite clauses are in turn complex, containing embedded object complements of the cognition verb sir- 'know'. The full structure of (13) is schematically represented in Figure 10.

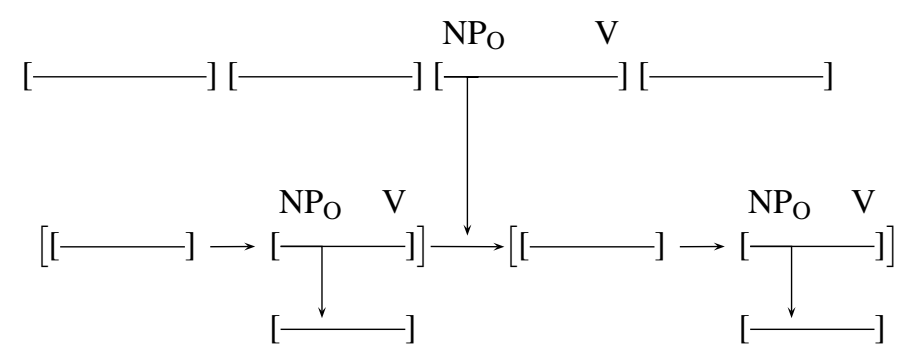

Figure 10. Full structure of example (13)

The top line of the diagram has the four chained clauses at the superordinate level (as in Figure 9). The third of these, with the quotative verb, has a complex embedded object, represented by the downward arrow and all the material below it. This consists of two complex sentences (in large brackets) chained together. Each of these sentences in turn contains a chain of two clauses, the second of which in each case contains an embedded complement, the lowest level of the diagram.

One cannot help but appreciate the amazing complexity created by the repeated combination of chaining and embedding architectures in the construction of this sentence. Recall that this example was produced spontaneously, 
in the middle of an oral narrative. The production of this sentence was fluent and effortless, and speakers have no difficulty following the twists and turns of clauses to extract the intended meaning. This is due to a combination of morphological and prosodic cues that serve to guide the hearer through the sentence.

\section{Levels of juncture}

As we have seen, the free combination of chaining and embedding architectures allows for limitless variety in the configuration of sentences. Yet these two principles alone do not tell the entire story; there is a cross-cutting feature of clause combining which adds additional subtlety to the syntactic labyrinths produced by the recursive structures. This is juncture: the chaining of units at syntactic levels below the clause. Consider example (14):

$$
\begin{aligned}
& \bar{a} l e \text { budā jā na-i-ta } \quad \text { on-nasin } \text { [thõsi=e kawāph } \\
& \text { then old.man rice eat-INF-PURP go-WHEN meat=GEN ball } \\
& \text { dak-e hä-en ta-e }]_{\mathrm{NP}-\mathrm{O}} \text { khon-ai } \\
& \text { make-PART bring-PART put-NR2 see-3sG.PR } \\
& \text { 'Then when the old man went in order to eat rice, he saw that (she) } \\
& \text { had made, brought, and put meatballs.' }
\end{aligned}
$$

The basic syntactic structure of this example comprises two adverbial clauses (one purposive and one temporal) followed by a finite clause. The finite clause contains an embedded complement, which consists of three clauses in linear order, linked by the participial construction. Following the diagramming conventions above, the basic structural configuration can be represented as in Figure 11.

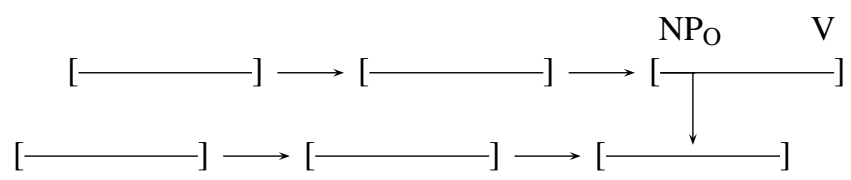

Figure 11. Example (14): A three-unit chain embedded as an object complement in the final clause of a three-unit chain

However, this simple schematic diagram does not do justice to the complexity of this sentence. Chaining structures do not always chain full clauses. They can also be used to chain verbs or verb phrases (which I define for this language as a syntactic constituent containing all clausal elements except the subject; Genetti 2007: 454). Similar phenomena in other languages have been 
discussed in the literature on "juncture" in Role and Reference Grammar (Foley \& Van Valin 1984: 244-264, Van Valin \& LaPolla 1997: 442-448, Van Valin 2005: 183-204). That framework proposes a three-layered structure of the clause, and the joining of elements at the nuclear (roughly verbal), core (roughly predicate), and peripheral (roughly clausal) levels. ${ }^{8}$

Putting aside the embedded complement for the moment, the primary constituents of (14) can be represented as in (15), elaborated to show sub-clausal constituency:

$$
\begin{aligned}
& {\left[\mathrm{NP}_{\text {SUBJ }}[\mathrm{VP} \rightarrow \mathrm{VP} \rightarrow \mathrm{VP}]_{\text {CHAIN.VP }}\right]_{\text {SENTENCE }}} \\
& \text { budā } j \bar{a} \text { na-i-ta on-nasin ... khon-ai } \\
& \text { old.man rice eat-INF-PURP go-when ... see-3PST }
\end{aligned}
$$

Here we have a single subject noun phrase, followed by a set of three chained verb phrases, two transitive and one intransitive. Note that the subject noun phrase is not case-marked. In this language, when you have a chained structure with a single subject noun phrase, the case-marking on that noun phrase can reflect the transitivity of any of the verbs in the chain, with no apparent implication for semantic, syntactic, or pragmatic interpretation. I refer to this syntactic feature as "case prolepsis" (Genetti 2007: 450-455). The existence of case prolepsis argues that the initial nominal is the single grammatical subject, which holds grammatical relations with each verb in the chain. The three chained verb phrases together form a complex verb phrase for the single subject nominal, which can be case-marked in accordance with the transitivity of any of the verbs in the chain.

Let us now add to this diagram the embedded complement.

(16)

$$
\begin{aligned}
& {\left[\mathrm{NP}_{\text {SUBJ }}[\mathrm{VP} \quad \rightarrow \mathrm{VP} \quad \rightarrow \quad V P]_{\text {CHAIN.VP }}\right]_{\text {SENTENCE }}} \\
& \text { budā } \quad j \bar{a} \text { na-i-ta on-nasin } \quad \ldots \text { khon-ai } \\
& \text { old.man rice eat-INF-PURP go-when } \quad \ldots \text { see-3PR }
\end{aligned}
$$

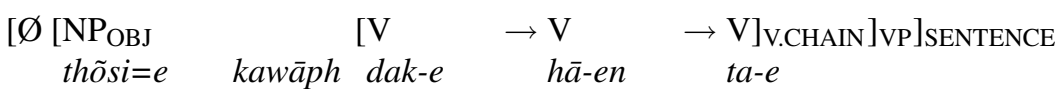

$$
\begin{aligned}
& \text { meat }=\text { GEN ball make-PART bring-PART put-NR2 }
\end{aligned}
$$

While the chaining structure at the top level applies at the level of verb phrase, joining constituents comprising verbs and their objects, the chaining in the embedded complement applies at the level of the verb. The three verbs chained

8. As the levels of nuclear, core, and periphery as defined in Role and Reference Grammar do not align perfectly with clausal structures in Dolakha Newar, I do not adopt these terms here. 
together form a complex verbal expression, which takes the single noun phrase thõsi=e kawāph 'meatball' as its object.

We can thus see that the structures created by chaining are more subtle than they first appear, creating complexity internal to the verb phrase, internal to the clause, and internal to the sentence. The distinct levels of juncture multiply the number of possible structures produced by the combination of chaining and embedding. Clause boundaries become blurred as chains are constructed at the sub-clausal level. Noun phrases are linked with multiple verbs, interweaving the grammatical relations like threads in a complex tapestry.

\section{The congruence of features that shape a core linguistic system}

We have seen that in Dolakha Newar the principles of chaining and embedding together produce an efficient system that is central to the syntax and to the production of connected discourse. Many languages of the world have chaining structures, many have embedding, and recursion has been claimed to be a universal feature of language (amid some recent controversy). So what is it that gives these features their central nature in the grammar of Dolakha Newar? The answer is a fortunate congruence of typological, areal, and language-particular features that synthesize into the flexible and productive system depicted here.

Typological features include the verb-final constituent order: positioning the verb at the end of the clause renders it the locus for the marking of continuity and finality. This is especially true as the verb often occurs as the final element of a prosodic phrase, and so is frequently the target of prosodic lengthening and carries the primary boundary tone. This increases its salience as the primary indicator signaling the speaker's intention to continue or end the sentence, and makes it a natural target for the grammaticalization of clause-linkage morphology, such as converbal suffixes (which may develop from case-markers, nominalizers, conjunctions, or other elements). Together, the morphological and prosodic cues function as signposts that guide hearers through the complex twists and turns of syntactic structures.

Areal features that have influenced the development of Dolakha Newar grammar include the frequent use of recapitulation in narrative, which creates an environment for the adjunction of a chain of clauses at sentence beginnings, and the stringing together of verbs, in serial or morphologically marked structures, with few conjunctions indicating the varying syntactic and semantic relationships that hold between clauses.

Language-particular grammatical features then work within the broader typological and areal context to give the Dolakha Newar system its clarity and complexity. First, the language makes a consistent morphological distinction between finite and non-finite verbs, and this distinction correlates with the finality versus non-finality of the sentence. Speakers use finite suffixes when 
they have reached a significant end. Non-finite suffixes are used in non-final contexts; they link a verb, verb phrase, or clause to another unit which follows it. Indeed every time a speaker produces a verb at the end of a clause, he or she is at a decision point, and is required to signal whether the sentence will be closed off by the production of a finite verb, or continued by the production of a non-finite verb specifically marked for its relationship to what follows. This process of decision making allows for speakers to build up sentences incrementally ${ }^{9}$ and to progressively construct increasingly complex syntactic edifices. The use of a non-finite suffix will instantiate either a chaining or an embedding structure.

The second language-particular feature which enables the remarkable complexity of sentences is the embedding of direct speech as complement objects of utterance verbs. This then allows entire sentences and sequences of sentences to be wholly embedded within the external structure of the quotative frame.

The third language-particular feature is the ability for chains to link elements at sub-clausal levels, allowing strings of verbs or verb phrases to share single noun phrase arguments, as evidenced by case prolepsis. Chaining at the level of the verb and verb phrase results in the muting of clausal boundaries, and gives a greater level of subtlety and nuance to syntactic structures. Clauses are not in simple linear order like beads on a string; instead groups of verbs or verb phrases hold grammatical relations with shared arguments, creating structures that are more complex than our standard notion of a clause.

Together, these features combine to allow for the simple, yet infinitely variable, grammatical system of clause combining in Dolakha Newar. Speakers exploit these resources with remarkable ease and frequency; indeed, singleclause sentences are rare in narrative discourse and unusual in conversational speech. Embedding and chaining architectures are central principles of design in this language, allowing the production of intricately interwoven, yet strongly bounded, sentences of subtlety, depth, and complexity.

Received: 13 September 2010

University of California, Santa Barbara

Revised: 8 December 2010

9. It may appear that the center embedding of direct-quote complements presents a counterexample to this claim, but this is not true if one sees the primary narrative line - and the syntax that instantiates it - as being suspended during the production of the direct quote. The production of the utterance verb explicitly marks the rhetorical shift from quote to main-line narrative and the corresponding resumption of the higher-level syntactic frame, which the speaker can then close off (with the production of a finite verb) or extend (with the production of a non-finite verb). 
Correspondence address: Department of Linguistics, University of California, Santa Barbara, Santa Barbara, CA 93106-3100 U.S.A.; e-mail: cgenetti@linguistics.ucsb.edu

Abbreviations: ABL ablative; ASs assertion; CL classifier; COMP complementizer; COND conditional; DAT dative; ERG ergative, FOC focus; FUT future; GEN genitive; IMP imperative; IND individuating; INF infinitive; INST instrumental; LOC locative; NEG negative; NR1 nominalizer/relativizer; NR2 nominalizer/relativizer; PART participle (converb); PL plural; PR present; PST past; PURP purpose; REC recipient SG singular.

\section{References}

Benedict, Paul K. 1972. Sino-Tibetan: A conspectus. Cambridge: Cambridge University Press.

Bickel, Balthasar. 1998. Converbs in cross-linguistic perspective. Linguistic Typology 2. 381-397.

Bradley, David. 1997. Tibeto-Burman languages and classification. In David Bradley (ed.) Papers in Southeast Asian linguistics no. 14: Tibeto-Burman languages of the Himalayas (Pacific Linguistics A-86), 1-72. Canberra: Australian National University.

Dixon, R. M. W. 2006. Complement clauses and complementation strategies in typological perspective. In R. M. W. Dixon \& Alexandra Y. Aikhenvald (eds.), Complementation: A crosslinguistic typology, 1-49. Oxford: Oxford University Press.

Dixon, R. M. W. 2009. The semantics of clause-linking in typological perspective. In R. M. W. Dixon \& Alexandra Aikhenvald (eds.), The semantics of clause linking: A cross-linguistic typology, 1-55. Oxford: Oxford University Press.

Fishman, Joshua A. 2001. From theory to practice (and vice versa): Review, reconsideration, and reiteration. In Joshua Fishman (ed.), Can threatened languages be saved? Reversing language shift revisited: A 21st century perspective, 451-483. Clevedon, UK: Multilingual Matters.

Foley, William \& Robert D. Van Valin, Jr. 1984. Functional syntax and universal grammar. Cambridge: Cambridge University Press.

Genetti, Carol. 1994. A descriptive and historical account of the Dolakha Newari dialect (Monumenta Serindica 24). Tokyo: Institute for the Study of Languages and Cultures of Asia and Africa.

Genetti, Carol. 1997. Object relations and dative case in Dolakha Newari. Studies in Language 21. 33-62.

Genetti, Carol. 2005. The participial construction in Dolakha Newar: Syntactic implications of an Asian converb. Studies in Language 29. 35-87.

Genetti, Carol. 2007. A grammar of Dolakha Newar (Mouton Grammar Library 40). Berlin: Mouton de Gruyter.

Genetti, Carol \& Keith Slater. 2004. An analysis of syntax/prosody interactions in a Dolakhā Newār rendition of the Mahābhārata. Himalayan Linguistics 3. 1-91.

Glover, Warren. 1970. Cognate counts via the Swadesh list in some Tibeto-Burman languages of Nepal. In Frederic K. Lehman (ed.), The tone systems of Tibeto-Burman languages of Nepal (Occasional Papers of the Wolfenden Society on Tibeto-Burman Languages 3), Vol. 2, 23-36. Urbana, IL: Department of Linguistics, University of Illinois.

Kansakar, Tej Ratna. 1999. The syntactic typology of Newar and Tamang languages. Gipan 1(1). $1-42$.

König, Ekkehard. 1995. The meaning of converbal constructions. In Martin Haspelmath \& Ekkehard König (eds.), Converbs in cross-linguistic perspective: Structure and meaning of adverbial verb forms, 57-95. Berlin: Mouton de Gruyter.

Longacre, Robert. 1968. Philippine languages: Discourse, paragraph, and sentence structure. Santa Ana, CA: Summer Institute of Linguistics.

Longacre, Robert E. 1985. Sentences as combinations of clauses. In Shopen (ed.) 1985, 235-286.

Masica, Colin. 1991. The Indo-Aryan languages. Cambridge: Cambridge University Press.

Matisoff, James A. 1969. Verb concatenation in Lahu: The syntax and semantics of "simple" juxtaposition. Acta Linguistica Hafniensia 12. 69-120. 
Matisoff, James A. 1973. A grammar of Lahu (University of California Publications in Linguistics 75). Berkeley, CA: University of California Press.

Rude, Noel. 1985. Studies in Nez Perce grammar and discourse. Eugene, OR: University of Oregon dissertation.

Rude, Noel. 1986. Topicality, transitivity and the direct object in Nez Perce. International Journal of American Linguistics 52. 124-153.

Shopen, Timothy (ed.). 1985. Language typology and syntactic description, Vol. 2: Complex constructions. Cambridge: Cambridge University Press.

Thompson, Sandra \& Robert Longacre. 1985. Adverbial clauses. In Shopen (ed.) 1985, 171-234.

van Driem, George. 2001. Mahakiranti revisited: Mahakiranti or Newaric. In Tej R. Kansakar \& Mark Turin (eds.), Themes in Himalayan languages and linguistics, 21-26. Heidelberg: South Asia Institute; Kathmandu: Tribhuvan University.

Van Driem, George. 2004. Newaric and Mahakiranti. In Anju Saxena (ed.), Himalayan languages: Past and present, 412-418. Berlin: Mouton de Gruyter.

Van Valin, Robert D. Jr. 2005. Exploring the syntax-semantics interface. Cambridge: Cambridge University Press.

Van Valin, Robert D. Jr. \& Randy J. LaPolla. 1997. Syntax: Structure, meaning, and function. Cambridge: Cambridge University Press.

Voegelin, Charles F. \& Florence M. Voegelin. 1977. Classification and index of the world's languages. New York: Elsevier.

de Vries, Lourens D. 2005. Towards a typology of tail-head linkage in Papuan languages. Studies in Language 29. 363-384. 